\title{
Study on Ornamental Characteristics and Propagation Technology of Bambusa Multiplex
}

\author{
Liangpu $\mathrm{QU}^{1}$, Hong $\mathrm{WU}^{2}$, Xia $\mathbf{L I}^{3}$ \\ Jiangsu Agri-animal Husbandry Vocational College, Taizhou 225300, China. \\ * Corresponding Author: Liangpu QU, engaged in ornamental plant cultivation, physiology, ecology \\ and application research

\begin{abstract}
To study the propagation technology of Bambusa multiplex. Comparison of rooting effect of Bambusa multiplex in different hormone concentration, different matrix formula, different planting season, and different planting season. The results showed that the best selection for propagation of Bambusa multiplex in spring was to adopt double-stage flat burying, soak in ABT1\# rooting powder at 200 ppm concentration for 2 hours, and the substrate was perlite, vermiculite, sandy soil and nutrient soil (1: 1: 1: 1: 1), the rooting rate could reach $50.00 \%$.
\end{abstract}

Keywords: Bambusa multiplex, Ornamental characteristics, Burial propagation, Study

\section{INTRODUCTION}

Bambusa multiplex belongs to the genus Phyllostachys in Gramineae, and is a cluster bamboo. Stem height $3-6 \mathrm{~m}$, diameter $0.5-1 \mathrm{~cm}$, tip slightly curved, internode hollow, length $16-20 \mathrm{~cm}$, leaf $9-13$, leaf length $3.3-6.5 \mathrm{~cm}$, width $4-7 \mathrm{~mm}$. Culm dark green, culm ring inconspicuous, culm ring with wooden peg ring and prominent uplift or turn down, branches mostly. The shoot period is longer, from April to October germination of new shoots, shoots can last for 3-6 months ${ }^{[1-2]}$. Slender branches and leaves, stems slightly bent down, like a phoenix tail, natural and unrestrained, elegant appearance beautiful and elegant, can give a person with a fresh and refreshing feeling, high ornamental value, suitable for planting in the courtyard in the corner, corner, door, and rockery, stacked stone, elegant chic. This can also be used as bonsai plants, with rocks, ornaments. Bamboo leaves slender and soft, natural and unrestrained charm, yin-resistant, so it is in-door and outdoor good foliage, shape plants.

Bambusa multiplex originated in the south of the Yangtze river basin in China, commonly used branch breeding, but because of its clustered bamboo each section of the cluster of branches, main branches and side branches have hidden buds, under certain conditions also have adventitious roots, so it can also be used to reproduce, and this method does not destroy the underground part of the bamboo cluster, can be combined with pruning, with cutting and cutting, material is convenient, but at present, few people do related research, Zheng Wei ${ }^{[3]}$ has used section cutting propagation.

The test site is in the greenhouse of Jiangsu agriculture and animal husbandry science and technology vocational college, hailing district, Taizhou city, Jiangsu province. The geographical coordinates are 3201 ' 57 " north latitude and 119 38' 24 " east longitudes. The regional seasonal distribution is obvious, the general summer heat, rainfall is large, less rainfall in winter. The annual average temperature is between $14.4^{\circ} \mathrm{C}$ and $15.1{ }^{\circ} \mathrm{C}{ }^{[4]}$.

\section{Materials AND Methods}

\subsection{Material Selection and Fabrication}

The tested bamboo species is Bambusa multiplex in the high-quality bamboo garden of the campus base. 2-3-year-old bamboo rods with robust growth, full stalk buds, no disease and insect pests and strong germination ability are selected, and the middle and lower parts of the bamboo crown with green branches or light-yellow branches are sufficiently exposed to light, and the tops are cut off, and the middle and upper parts are reserved ${ }^{[5]}$. According to the experimental design requirements were cut into single-segment and double - segment, upper incision flat shear, remove redundant parts and branches and leaves, internode properly keep some branches and leaves, to facilitate photosynthesis. 


\subsection{Experiment Design}

\subsubsection{Comparison of Different Hormone Concentration}

The single-section flat burying method is adopted. The matrix is composed of perlite, vermiculite, sandy soil and nutrient soil (1:1:1:1). Hormone with $\mathrm{ABT}^{\#}{ }^{\#}$ rooting powder and NAA, set different gradients, such as clear water as the control, using random group arrangement of 3 repeats, each treatment 30 knots. See table 1 below for specific concentration and soaking time:

Table1. Different Hormone Concentrations and Treatment Schedule

\begin{tabular}{|l|l|}
\hline \multicolumn{1}{|c|}{ Different hormones } & \multicolumn{1}{c|}{ Root powder concentration and treatment time } \\
\hline Pure water (CK) & immersion in Clear water \\
\hline $\mathrm{ABT}^{1 \#}$ & $200 \mathrm{ppm}(2 \mathrm{~h})$ \\
\cline { 2 - 2 } & $400 \mathrm{ppm}(2 \mathrm{~h})$ \\
\cline { 2 - 2 } & $800 \mathrm{ppm}(1 \mathrm{~h})$ \\
\cline { 2 - 2 } & $1000 \mathrm{ppm}(15 \mathrm{~s})$ \\
\cline { 2 - 2 } & $1500 \mathrm{ppm}(15 \mathrm{~s})$ \\
\hline NAA & $200 \mathrm{ppm}(2 \mathrm{~h})$ \\
\cline { 2 - 2 } & $400 \mathrm{ppm}(2 \mathrm{~h})$ \\
\cline { 2 - 2 } & $800 \mathrm{ppm}(1 \mathrm{~h})$ \\
\cline { 2 - 2 } & $1000 \mathrm{ppm}(15 \mathrm{~s})$ \\
\cline { 2 - 2 } & $1500 \mathrm{ppm}(15 \mathrm{~s})$ \\
\hline
\end{tabular}

Increasing the concentration in a certain concentration range has the effect of increasing the rooting rate, but to a certain extent, increasing the negative impact, so there is the concept of optimal concentration.

\subsubsection{Different Matrix Ratio}

Five kinds of substrates with different formulations were used to test the rooting of Bambusa multiplex. The segments of Bambusa multiplex were soaked with abt 1 \# 200 ppm for 2 hours, and the effects of different substrate formulations on the rooting of Bambusa multiplex were compared. Three repetitions were arranged using a random block group, each processing 30 sections.

Table2. Comparison of Different Matrices

\begin{tabular}{|l|l|}
\hline \multicolumn{1}{|c|}{ Number } & \multicolumn{1}{c|}{ Matrix Ratio } \\
\hline 1 & Perlite, vermiculite, sandy soil, nutrient soil $(1: 1: 1: 1)$ \\
\hline 2 & Nutrient soil + perlite $(1: 1)$ \\
\hline 3 & Sand \\
\hline 4 & Coconut bran \\
\hline 5 & Sand + garden soil $(1: 1)$ \\
\hline
\end{tabular}

\subsubsection{Time Comparison of Different Buried Joints}

In order to summarize the seasonal effects, the single-section flat burying method was used to select the formula perlite, vermiculite, sandy soil and nutrient soil(1:1:1:1:1:1) as the substrate, and the experiment was conducted in spring of 2015 and autumn of September of 2015 by ABT1 \# 200 ppm ( $2 \mathrm{~h}$ ) concentration treatment.

\subsubsection{Comparison of Different Section Lengths and Buried Sections}

The length of cuttings and the way of burying joints may influence rooting. In this experiment, the formula 1: perlite, vermiculite, sandy soil and nutrient soil (1:1:1:1:1) were used as the matrix, and ABT1 \# 200 ppm was used to soak for 2 hours (double bamboo joints were drilled in the middle of bamboo joints), and the rooting effect was compared. Three repetitions were arranged using a random block group, each processing 30 sections.

Table3. Comparison of Different Buried Joints

\begin{tabular}{|l|l|}
\hline \multicolumn{1}{|c|}{ Number } & \multicolumn{1}{c|}{ Buried joint mode } \\
\hline 1 & Single section flat burying \\
\hline 2 & Single section inclined buried $\left(45^{\circ} \mathrm{C}\right)$ \\
\hline
\end{tabular}




\begin{tabular}{|l|l|}
\hline 3 & Double - section flat burying \\
\hline 4 & Double inclined buried $\left(45^{\circ} \mathrm{C}\right)$ \\
\hline
\end{tabular}

\subsection{Test Management}

The test was conducted on April 14, 2015 (The season test begins in September 5th), and the substrate used in the test was sterilized with $0.5 \%$ aqueous potassium permanganate. Because the local temperature is still low in April, to guarantee the effect of rooting after cutting, put it into the greenhouse for daily maintenance and management, according to the greenhouse air humidity, flexible control of water spray management, maintain a reasonable air humidity, and keep the greenhouse air fresh circulation situation, in case of high temperature and humidity caused by disease and insect damage, and observe the germination and rooting.

\subsection{Results Statistics}

Each experiment was conducted at the end of May (season test including the end of October) to investigate the rooting rate of cuttings, calculate the survival rate, and fill in the record form carefully. After data acquisition, single factor analysis of variance was carried out by excel and related statistical analysis tools, and the results were obtained by using the new complex polar difference method.

\section{RESUlTS AND ANALYSIS}

\subsection{Effects of Different Hormone and Concentration Treatment on Rooting of Bambusa Multiplex}

Table4. Effects of Different Hormone Treatments on Rooting of Bambusa Multiplex

\begin{tabular}{|l|l|l|l|l|l|}
\hline $\begin{array}{c}\text { Different } \\
\text { hormones }\end{array}$ & $\begin{array}{c}\text { Root powder concentration } \\
\text { and treatment time }\end{array}$ & Repeat 1 & Repeat2 & Repeat 3 & \multicolumn{1}{c|}{$\begin{array}{c}\text { Average } \\
\text { rooting rate }\end{array}$} \\
\hline Pure water (CK) & Soaked in water & 3.33 & 6.67 & 0.00 & $3.33 \mathrm{dC}$ \\
\hline \multirow{4}{*}{$\mathrm{ABT}^{1 \#}$} & $200 \mathrm{ppm}(2 \mathrm{~h})$ & 36.67 & 33.33 & 43.33 & $37.78 \mathrm{aA}$ \\
\cline { 2 - 6 } & $400 \mathrm{ppm}(2 \mathrm{~h})$ & 26.67 & 33.33 & 20.00 & $26.67 \mathrm{bB}$ \\
\cline { 2 - 6 } & $800 \mathrm{ppm}(1 \mathrm{~h})$ & 10.00 & 3.33 & 0.00 & $4.44 \mathrm{dC}$ \\
\cline { 2 - 6 } & $1000 \mathrm{ppm}(15 \mathrm{~s})$ & 3.33 & 0.00 & 0.00 & $1.11 \mathrm{dC}$ \\
\cline { 2 - 6 } & $1500 \mathrm{ppm}(15 \mathrm{~s})$ & 0.00 & 0.00 & 3.33 & $1.11 \mathrm{dC}$ \\
\hline \multirow{3}{*}{ NAA } & $200 \mathrm{ppm}(2 \mathrm{~h})$ & 23.33 & 16.67 & 30.00 & $23.33 \mathrm{bcB}$ \\
\cline { 2 - 6 } & $400 \mathrm{ppm}(2 \mathrm{~h})$ & 16.67 & 20.00 & 16.67 & $17.78 \mathrm{cB}$ \\
\cline { 2 - 6 } & $800 \mathrm{ppm}(1 \mathrm{~h})$ & 6.67 & 6.67 & 0.00 & $4.45 \mathrm{dC}$ \\
\cline { 2 - 6 } & $1000 \mathrm{ppm}(15 \mathrm{~s})$ & 0.00 & 6.67 & 0.00 & $2.22 \mathrm{dC}$ \\
\cline { 2 - 6 } & $1500 \mathrm{ppm}(15 \mathrm{~s})$ & 0.00 & 0.00 & 0.00 & $0.00 \mathrm{dC}$ \\
\hline
\end{tabular}

The results of rooting treatment of Bambusa multiplex with different hormones and concentrations (table 4) showed that plant growth regulator had a significant effect on rooting, and the rooting rate of Bambusa multiplex was significantly higher than that of control after treatment with $\mathrm{ABT}^{1 \#}$, NAA. $\mathrm{ABT}^{1 \#}$ rooting powder was soaked at $200 \mathrm{ppm}$ for $2 \mathrm{~h}$, the rooting rate of phoenix tail bamboo was $37.78 \%$ and $400 \mathrm{ppm}$ for $2 \mathrm{~h}$, the rooting rate was $26.67 \%$. When the NAA concentration was $200 \mathrm{ppm}$ for $2 \mathrm{~h}$, the rooting rate was $23.33 \%$ of the control, the difference was significant at 0.01 levels and 0.05 levels. Compared with $3.33 \%$ of the control, the difference was significant at 0.01 levels and 0.05 levels. Compared with $\mathrm{NAA}, \mathrm{ABT}^{1 \#}$ rooting powder was more favorable to the rooting of Bambusa multiplex

The data in the table also show that the growth regulator concentration has a great effect on rooting, $\mathrm{ABT}^{1 \#}$ rooting powder mass concentration of $800 \mathrm{ppm}$ for $1 \mathrm{~h}$, the rooting rates only $4.44 \%$ and 1000 ppm, $1500 \mathrm{ppm}$ dip treatment after the rooting rate is lower, only $1.11 \%$; The rooting rate of NAA was only $4.45 \%$ at $800 \mathrm{ppm}$ and $2.22 \%$ at $1000 \mathrm{ppm}$ and $0.00 \%$ at $1500 \mathrm{ppm}$, respectively the results are consistent with those of Sun Zhong yuan et al ${ }^{[6]}$.

\subsection{Effects of Different Matrix Ratios on Rooting of Bambusa Multiplex}

As can be seen from the data in table 5, different matrix formulations have a significant effect on the rooting of Bambusa multiplex. The results showed that the final rooting rate was $37.78 \%$ for perlite, vermiculite, sandy soil and nutrient soil (1: 1: 1: 1), but only $3.33 \%$ for pure coconut bran in formula 4. The rooting rate of pure coconut bran in several formulas was significantly different. Analysis of 
the reasons, formula 1 contains perlite, vermiculite, sandy soil, nutrient soil and other mixed matrix, not only can ensure the loose ventilation, good moisturizing effect, but also have sufficient nutrients, strong matrix fixation ability, fully fit with the phoenix tail bamboo section, bamboo section to ensure moisture, so as to facilitate rooting; Although the sand in formula 3 has strong permeability, the water and fertilizer retention capacity is poor, the water is easy to lose, the heat preservation effect is poor, the rooting rate is slightly lower, only $13.34 \%$, the moisture must be fully guaranteed during the curing period, and the fertilizer application should be paid attention to in the later period to ensure the nutrient supply; Formula 4 coconut bran has the lowest rooting rate, only $3.33 \%$, although coconut bran has good pore structure and strong water retention capacity, but the texture is lighter, bamboo is different from other plants, in the propagation of buried joint with bamboo segment adhesion is not strong, adhesion is not high, but make the joint with soil closely affect the rooting effect.

Table5. Effects of Different Matrix Ratios on Rooting of Bambusa Multiplex

\begin{tabular}{|l|l|l|l|l|l|}
\hline \multicolumn{2}{|c|}{ Different matrix ratio } & Repeat 1 & Repeat 2 & Repeat 3 & Average rooting rate \\
\hline Process 1 & $\begin{array}{l}\text { Perlite, vermiculite, sandy soil, } \\
\text { nutrient soil (1: 1: 1: 1) }\end{array}$ & 36.67 & 33.33 & 43.33 & $37.78 \mathrm{aA}$ \\
\hline Process 2 & Nutrient soil + perlite (1: 1) & 30.00 & 20.00 & 16.67 & $22.22 \mathrm{bB}$ \\
\hline Process 3 & Sand & 6.67 & 16.67 & 16.67 & $13.34 \mathrm{bcBC}$ \\
\hline Process 4 & Coconut bran & 6.67 & 3.33 & 0.00 & $3.33 \mathrm{cC}$ \\
\hline Process 5 & Sand + garden soil (1: 1) & 20.00 & 23.33 & 16.67 & $20.00 \mathrm{bB}$ \\
\hline
\end{tabular}

\subsection{Effects of Different Burying Methods on Rooting of Bambusa Multiplex}

The data in table 6 show that different burying modes have little effect on rooting effect and no significant difference, but the rooting rate is relatively higher than that of the inclined burying, and the bamboo segments may be fully contacted with the substrate during the horizontal burying, and the moisturizing effect is better to facilitate rooting. The rooting rates of single-section flat burying and inclined burying were $37.78 \%$ and $32.22 \%$, respectively. The rooting rates of double-section flat burying and inclined burying were $50.00 \%$ and $45.55 \%$, respectively. The difference reached a significant level. These data indicated that the effect of double-section flat burying was better than that of single-section bamboo planting. Buried - node seedling raising is to use the full dormant buds on the stem nodes as the root base, and the nutrients of the bamboo nodes themselves as the energy source before rooting, the rooting process needs to consume a large amount of nutrients and capacity, the storage of carbohydrates in the bamboo nodes have an important effect on rooting, the higher the ratio, the higher the rooting rate ${ }^{[7-9] .}$

Table6. Effects of different burying methods on rooting of Bambusa multiplex

\begin{tabular}{|l|l|l|l|l|l|}
\hline & Different buried joint modes & Repeat 1 & Repeat 2 & Repeat 3 & $\begin{array}{l}\text { Average } \\
\text { rooting rate }\end{array}$ \\
\hline Process 1 & Single section flat burying & 36.67 & 33.33 & 43.33 & $37.78 \mathrm{bcA}$ \\
\hline Process 2 & Single section inclined buried $\left(45^{\circ} \mathrm{C}\right)$ & 30.00 & 26.67 & 40.00 & $32.22 \mathrm{cA}$ \\
\hline Process 3 & Double - section flat burying & 43.33 & 50.00 & 56.67 & $50.00 \mathrm{aA}$ \\
\hline Process 4 & Double inclined buried $\left(45^{\circ} \mathrm{C}\right)$ & 53.33 & 40.00 & 43.33 & $45.55 \mathrm{abA}$ \\
\hline
\end{tabular}

\subsection{Effects of different burying seasons on rooting}

The effects of spring and autumn on rooting of buried season were compared. The results (table 7) showed that the rooting rate in spring (37. $78 \%$ ) was higher than that in autumn (15.56\%), although the difference was not significant, it had a certain improvement effect. The reason is that the shoot period of Bambusa multiplex is longer, and new shoots are germinated continuously from April to October. In April, the number of shoots is smaller; the nutrient loss of parent plant is lower. By September, the end of shoots is basically reached, the nutrient loss is too much, and the nutrient substances in parent plant are relatively less. Therefore, the planting season is not conducive to its rooting, and the planting season is the best in April to May.

Table7. Effects of Different Treatment Time on Rooting of Bambusa Multiplex

\begin{tabular}{|l|l|l|l|l|l|}
\hline Different buried seasons & Repeat 1 & Repeat 2 & Repeat 3 & Average rooting rate \\
\hline Process 1 & Spring (April) & 36.67 & 33.33 & 43.33 & $37.78 \mathrm{aA}$ \\
\hline Process 2 & Autumn (September) & 13.33 & 26.67 & 6.67 & $15.56 \mathrm{aA}$ \\
\hline
\end{tabular}




\section{DISCUSSION}

Hormone had a great effect on the propagation of Bambusa multiplex. The rooting rate was only $3.33 \%$ after soaking in clear water. The effect of $\mathrm{ABT}^{1 \#}$ was better than NAA. Both $\mathrm{ABT}^{1 \#}$ rooting powder and NAA mass concentration were $200 \mathrm{ppm}$ soaked for $2 \mathrm{~h}$, and the rooting rate was $37.78 \%$ and $23.33 \%$ respectively. The difference was significant, and high concentration was not conducive to rooting. But this experiment only uses abt1 \# rooting powder and NAA two hormones, for the effect of other rooting hormone and how to use together to play a better effect, and so on, including whether lower concentrations such as $50-100 \mathrm{ppm}$ is more conducive to the rooting of the phoenix tail bamboo segments also need to be further verified.

There were significant differences in rooting rate of Bambusa multiplex in different matrix proportions. formula 1: perlite, vermiculite, sandy soil and nutrient soil (1:1:1:1:1) had the best effect, the rooting rate reached $37.78 \%$, which may be related to the water retention, air permeability and heat preservation properties of the matrix itself. But also pay attention to the degree of close adhesion between the matrix and the phoenix tail bamboo section, like the coconut bran in formula 4 although there is strong permeability and sufficient fertility, but the matrix is too soft, but make the bamboo section and soil joint is not close enough to affect the rooting effect.

The rooting effect of Bambusa multiplex was not affected by the mode of burying joints, but the rooting rate of Bambusa multiplex was higher than that of oblique burying. The rooting rates of single and double segments were $37.78 \%$ and $50.00 \%$ respectively, while those of single and double segments were $32.22 \%$ and $45.55 \%$ respectively, which indicated that double segments were more favorable for rooting and nutrient accumulation in double bamboo segments was more helpful for rooting and increased rooting rate.

Different cutting seasons influence the rooting rate of Bambusa multiplex in the buried season, generally spring is good, the rooting rate can reach $37.78 \%$, which may be related to the spring air humidity, moisture content and nutritional status is higher than the autumn, Bambusa multiplex shoots from April to October, until September has reached the end of the shoot, the mother plant nutrient loss is too much, which influences rooting. The experiment design only compares the spring and autumn cottage, but the effect of summer and winter on rooting rate is not studied.

\section{CONCLUSiON}

Comprehensive comparison, the best choice for propagation of Bambusa multiplex is to adapt to double stage flat burying in spring, soak in ABT1\# rooting powder with $200 \mathrm{ppm}$ concentration for 2 hours and the highest rooting rate can reach $50.00 \%$ by using perlite, vermiculite, sandy soil and nutrient soil ( 1: 1: 1: 1: 1 ). In the experiment, management methods such as water, humidity, temperature and so on may have certain influence on rooting rate, which needs further study.

\section{ACKNOWLEDGMENT}

This work is supported by the general program of Jiangsu Agri-animal Husbandry Vocational College (No. NSFYB1411).

\section{REFERENCES}

[1] Geng Bojie, Wang Zhengping. Chinese flora: Gramineae (1): Bamboo subfamily: ninth volumes: first copies [M]. Beijing: Science Press, 1996.

[2] Yi Tongpei, Shi Yijun. Chinese bamboo atlas. [M]. Beijing: Science Press, 2008.

[3] Zheng Wei. Cutting propagation of Bambusa multiplex, Home garden, 2010, 4:23.

[4] Chen Yijian. Study on the growth rhythm and cottage propagation technique of bamboos [D]. Fujian Agriculture and Forestry University. 2008.

[5] Wang Tao. Plant Cottage Propagation Technology [M]. Beijing: Beijing science and Technology Press, 1989.

[6] Sun Zhongyuan, Ma Yanjun, GAO Jian. Cutting and planting of bamboo shoots and planting techniques. Journal of Northeast Forestry University, 2013, 41 (9): 14-18.

[7] Hsiung W, Din Z, Li Y, et al. Studies on branching pattern of monopodial bamboos M / A N / Rao, Dhanaranjan G, Sastry CB. Recent research on bamboos: Proceedings of the international bamboo workshop. Hangzhou: CAF / IDRC, 1985: 128135. 
[8] Zhao Xiaomin, Huo Changfu, Shen Hailong. An overview of the internal and environmental factors affecting the rooting of tree cuttings [J]. World forestry research, 2007, 20 (5): 12 - 16.

[9] Rein, W. H., R. D. Wright, and D. D. Wolf. Stock plant nutrition influences the adventitious rooting of 'Rotundifolia' holly stem cuttings. Journal of Environmental Horticulture, 1991, 9 (2): 8385.

Citation: QU Liangpu et al., "Study on Ornamental Characteristics and Propagation Technology of Bambusa Multiplex", International Journal of Forestry and Horticulture, vol. 4, no. 1, p. 29-34, 2018. http://dx.doi.org/ 10.20431/2454-9487.0401005

Copyright: (C) 2018 Authors. This is an open-access article distributed under the terms of the Creative Commons Attribution License, which permits unrestricted use, distribution, and reproduction in any medium, provided the original author and source are credited. 